\title{
Article \\ Augmented Reality (AR) as a Tool for Engaging Museum Experience: A Case Study on Chinese Art Pieces
}

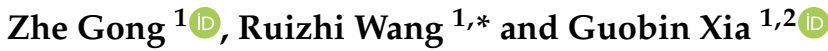 \\ 1 School of Design, University of Leeds, Leeds LS2 9JT, UK; sdzg@leeds.ac.uk (Z.G.); g.xia@hw.ac.uk (G.X.) \\ 2 School of Textiles and Design, Heriot-Watt University, Edinburgh TD1 3HF, UK \\ * Correspondence: sdrw@leeds.ac.uk; Tel.: +44-752-992-8855
}

check for updates

Citation: Gong, Z.; Wang, R.; Xia, G. Augmented Reality (AR) as a Tool for Engaging Museum Experience: A Case Study on Chinese Art Pieces. Digital 2022, 2, 33-45. https:// doi.org/10.3390/digital2010002 Academic Editor: Miguel Ángel Conde

Received: 6 December 2021 Accepted: 16 February 2022 Published: 20 February 2022

Publisher's Note: MDPI stays neutral with regard to jurisdictional claims in published maps and institutional affiliations.

Copyright: (c) 2022 by the authors Licensee MDPI, Basel, Switzerland. This article is an open access article distributed under the terms and conditions of the Creative Commons Attribution (CC BY) license (https:// creativecommons.org/licenses/by/ $4.0 /)$.

\begin{abstract}
The research explores the efficiency of augmented reality (AR) technology as a tool for the positive triggering museum experience. This article shows the design, development, and evaluation of an AR prototype for information visualization based on a famous Chinese art piece named Along the River During the Qingming Festival. In total, 58 participants were invited to evaluate the prototype. Results suggest that AR technology can trigger users' engagement, learning, meaningful experience, and emotional connection, and hence arouse their interest and learning process. These findings may interest researchers and designers to develop a broader range of innovative AR applications to prompt a digital learning experience.
\end{abstract}

Keywords: augmented reality; information visualization; human-computer interaction; digital learning experience

\section{Introduction}

Museums are seen as informal learning environments where the functions of collection, research, and exhibition, as well as education and recreation, are served. He, et al. [1] suggest that the success or failure of a user's general museum experience can be determined by perceived experiential value. Former research concludes that several domains as entertainment, enjoyment, visual appeal and escapism belong to experiential value generation in a museum context. [1-3]. Consistent with Black [4], leisure and entertainment, learning, new experiences, and entertainment in an engaging, stimulating environment are concentrated motivating aspects encompassing users' intentions to visit museums. Nevertheless, a common issue that most museums face is that it is often difficult for a wealth of information about famous collections to be fully understood by the general public without the provision of additional information $[5,6]$. To be specific, museums commonly provide text-based introductions to support visitors' learning purposes. This learning process involves time and an ability to analyze and understand visuals, and some visitors are not willing to spend time reading texts $[5,7,8]$. As a result, there is a need to develop newer methods to visualize the traditional text-based information that can engage people's interest, understanding, and learning processes.

\section{Background}

\subsection{Information Visualization and Cultural Heritage}

Information visualization is a computer-generated interactive graphical demonstration of information [9]. It is an interdisciplinary field concerning the visual representation of detailed information to improve people's understanding processes [10]. Moreover, information visualization can deliver insights about abstract information through a person's optical system function, and thus may serve as a helpful tool to support people to overcome rational difficulties [11], to think and reason [12], and to help them gain an in-depth understanding of information [13]. Furthermore, with its interdisciplinary nature, it has 
been appealed to the increasing academics from computer science, graphics, visual design, psychology, culture and humanities, and business. In particular, in the domain of art and culture heritage, the use of information visualization techniques to display detailed information visually, and the sustenance of interactive capabilities presents new possibilities for displaying information in informal learning places such as museums and art galleries. For example, Xia et al. [14] designed a series of interactive data physicalizing installations. They showed more positive effects on visitors' emotional and memorial responses than the conventional data visualizations [14].

\subsection{AR and Cultural Heritage}

Augmented reality (AR) technology is an emerging area that can potentially provide museums or art galleries with numerous valued and distinctive chances to raise access to their collections and increase people's learning and enjoyment. It was first introduced in the 1900 s as an idea for a digital presentation that overlaps data onto the physical world [15]. As noted, offering the unique ability to display computer-generated multimedia within the user's sphere of view, and blended within the nature world [16], augmented reality (AR) can be specified as a technique that boosts realistic feedback to the operator with simulated cues [17]. Azuma and Ronald [18] outlined three important characteristics of AR: a blend of real and virtual space; instantaneous interaction; and precise 3D registration of virtual and physical objects. Through combining the real and the virtual world, visual overlays can be viewed as part of learning support within the learning environment. For instance, Rosenbaum et al.Rosenbaum, et al. [19] illustrate the authentic feeling achieved in an AR learning environment which aids learners' comprehension and perception of dynamic models. It is found that AR environments also serve to increase learners' motivation and interest, which in turn may help develop their investigation skills and provide pathways for them to accrue a better knowledgebase regarding specific topics [20]. In particular, the immersive AR application can be used to improve learners' spatial abilities.

Furthermore, AR systems can support a diversity of teacher-student interaction scenarios [21-23], hence offering better opportunities to transfer knowledge and learning. Psychomotor-cognitive ability development could also be improved because AR can make use of visual cues and haptic cues, which can optimize users' experiences [24,25]. Sotiriou and BognerSotiriou and Bogner [20] discuss an AR system that was developed for clinical medicine, and they note that embedded in the physical environment were touch-sensors. These were used to collect sensor data that measured learners' performances, and this data was then transformed into visual feedback. Through AR technology, learners were able to receive real-time responses that could help them improve their performance levels and enhance their psychomotor skills when undertaking cognitive tasks. Chien, et al. [26] highlight that AR can to encourage kinesthetic learning, which focuses on experience, observation, activity, and experimentation. Augmented reality can create an immersive experience for learners in contextual education [27]. It could allow users to view learning content in 3D scenes. This is particularly beneficial for learners who typically have difficulty trying to visualize phenomena that are not feasible to consider in the physical world, not to mention complicated concepts. This can be achieved using AR by enabling learners to inspect 3D objects or course materials from various perspectives or angles to cultivate their understanding of the subject [28]. According to El SayedEl Sayed [29], AR systems and environments can help learners obtain skills and knowledge more efficiently than using other technology-enhanced learning contexts such as computers, multimedia, the internet, e-learning, and social networks. Collectively, AR, being an emerging technology, has excellent potential to improve this experience; it could arguably become a key player in the invaluable preservation of cultural heritage [30]. It is possible to utilize AR technology to provide additional information by way of physical operation. Doing so would also enable visitors to appreciate the interwoven nature of both the real world and the simulated images [28]. 
AR is usually best suited for mobile devices or a more immersive experience using head-mounted displays (HMDs). Especially for visiting purposes, it is equally important to design and implement an AR experience that carefully maximizes immersion in the experience and learning. However, researchers have raised concerns about the simulator sickness that HMDs may cause, including headache, disorientation, and nausea [31]. Therefore, mobile AR technology may provide more extraordinary abilities than HMDs in this context. A substantial amount of literature and academic articles address the concept of AR technology in ancient artworks. For example, the Cathedral of Valencia has its AR application. There is a reinforced interior of the existing central Gothic vault and closer access to Renaissance murals.

The fundamental purpose of that AR had been to allow users to visualize a Baroque vault that would have existed between 1682 and 2006 and to digitize it with a 3D ground laser scanner before removal [32]. The vault itself became the target image, and the concave vault surface was approximated to a planar feature. The application works property within a restricted area of $2 \mathrm{~m} \times 2 \mathrm{~m}$, just below the vault's centre; this is where the field geometrically matches the projected initially centre of the Baroque image. An additional issue was found concerning the lighting conditions when targeting the value, especially during daylight hours when the light floods through the stained-glass windows. Thus, the best environments are at night when the vault is lit with artificial light. Another example about AR in artwork, namely, the ARCO project, was launched in 2008. It concentrated on the museum end-user by developing simpler photogrammetry and manual modelling techniques.

Digital information was documented in a database to conduct a 3D rebuilding process with a 3D scanner. An AR plugin called AR toolkit was then used, and the virtual content was visualized in an AR environment. According to White et al. White, et al. [33], the museum houses a myriad of archives collections of artefacts that cannot otherwise be exhibited in a low-cost and straightforward way. Typically, museums may not have the space for all exhibits. As such, the ARCO project can be considered one of AR's successful capplications.

Another thing that is important to note is that visitors like to interact with exhibitions. Although tourists spend most of their time looking at exhibits, they still perform physical activities. Some studies show that the mobile guides in museum contexts can be classified into four different categories: (1) mobile guide applications, (2) web-to-mobile applications, (3) mobile phone navigational assistants, (4) mobile web-based applications [34]. Specifically, Panou et al. [35] developed an AR mobile guide application to explore historical information in text and images. Their research showed users' interest in investigating interest areas and unlocking historical information were prompted while winning points following an entrainment experience. A typical example of a web-to-mobile AR application is Google Maps. The audience can use their own devices to scan their surroundings and receive real-time information from websites [36]. Jung et al. [37] designed a VR/AR model visualization application, namely JejuView. Their results showed VR/AR model visualization application as an intuitive way to experience cultural heritage sites on the Jeju island. The online British Museum used AR technology that renders 3D models based on $2 \mathrm{D}$ graphics to present artefacts. The study was evaluated by 21 volunteers, reflecting a positive user experience [38].

Considering AR technology as the cheaper but more effective way to be exploited in museums, an important question is raised to study whether using AR to visualize the traditional text-based information can engage people's interest, understanding, and learning processes.

Derived from a multi-method research strategy, this research combines the design, development, and evaluation of an AR prototype (Figure 1) to investigate AR's effectiveness as a means for engaging interactive information visualization. This paper is organized into four sections. Section 2 specifies the design, development, and evaluation of the AR 
prototype used for this work; next, in Section 3, we examine the evaluation results; and finally, we offer a discussion and conclusion to the entire work in Section 4.

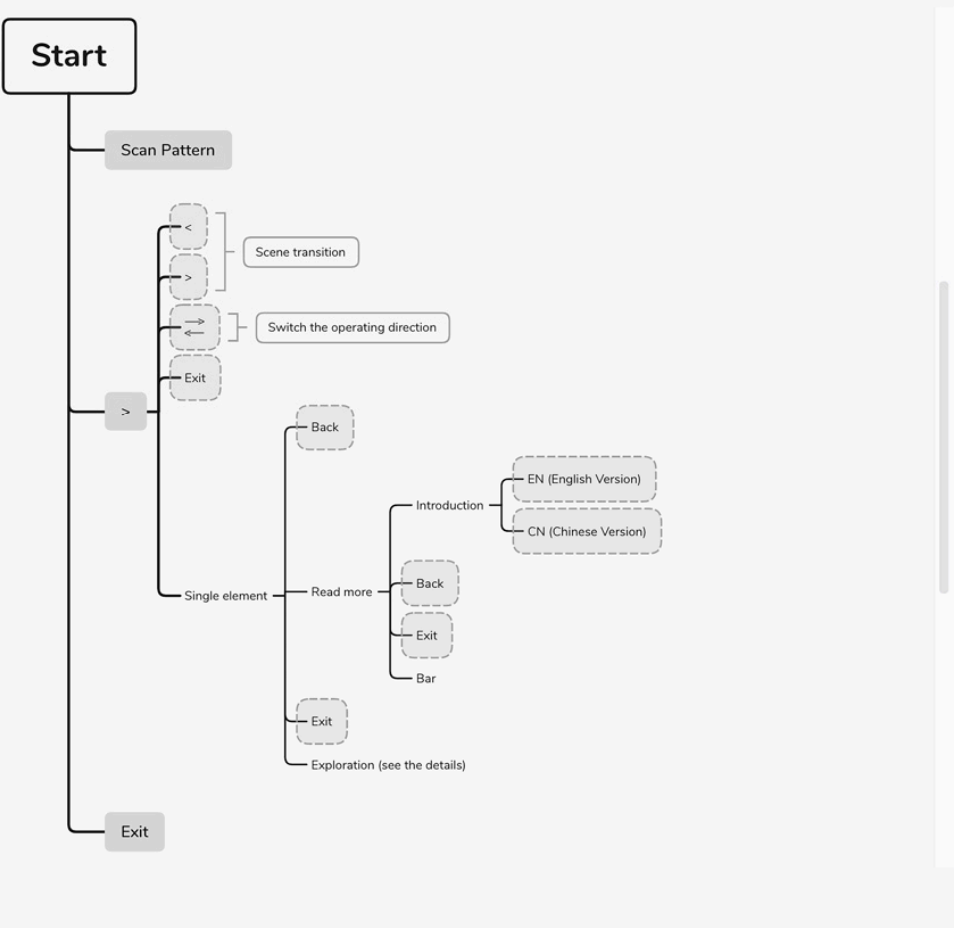

Figure 1. AR prototype processes flow diagram.

\section{Methods}

\subsection{Along the River during the Qingming Festival}

According to China's Palace Museum, the traditional Chinese long scroll painting, Along the River During the Qingming Festival, is considered the most distinguished masterpiece among all traditional Chinese paintings and is widely described as the Chinese Mona Lisa. In terms of Pan, et al. [39], the long scroll painting is $5.287 \mathrm{~m}$ long, portraying a typical scene in everyday life of people in the capital city of the Song Dynasty, Bianliang City. It stretches audiences an aerial view of the prosperous Bianliang city. The scroll depicts a lot of information, including 587 humans, 170 trees, 60 animals, 30 buildings, 28 boats, 20 vehicles, and eight sedan chairs. During the Song Dynasty, the original painting was created and considered a national treasure. It is exhibited for only a few months every 4 to 5 years. Thus, when it is on exhibition, many thousands of visitors come to look at the scroll in the Palace Museum. However, visitors cannot get close to the painting to appreciate its many details because of its popularity. The time when a visitor is allowed to see the painting is limited to just $5 \mathrm{~min}$. Visitors can only have a brief look at the painting, and thus there is limited time for any learning experience. In this case, the scroll is suitable for this article as it matches the issue described previously. As the painting is approximately $5 \mathrm{~m}$ long and contains a lot of information, it is impossible to create an interactive AR model of the entire painting; instead, the researcher selected the famous section from the painting the Rainbow Bridge.

\subsection{Design and Development}

In this study, a prototype combining augmented reality, visual aids, interaction, and learning support was created. Previous studies indicated that people do not want to read too much during their museum visits and do not wish to spend lots of time reading 
through texts $[7,8,40]$. One of the intended outcomes is that visitors will find the application appealing and will be motivated to learn more about the ink painting we are using following their visit to the museum.

The design and development process can be generally divided into three sections, including creating of the 3D meshes in terms of the original painting, rigging and animation process, and programming (Figures A1 and A2 in Appendix A). First of all, bridges, buildings, humans, boats, and vehicles of the Rainbow Bridge section were created in terms of the original painting. Then, all of these elements were rigged and animated. These meshes were exported to Unity to construct the AR and interactive functions (i.e., touch to display specific elements, detailed information regarding each item, see (Figure 2b,c). Sounds were also added to the environment. This project was tested using an Amazon Fire 7 pad.
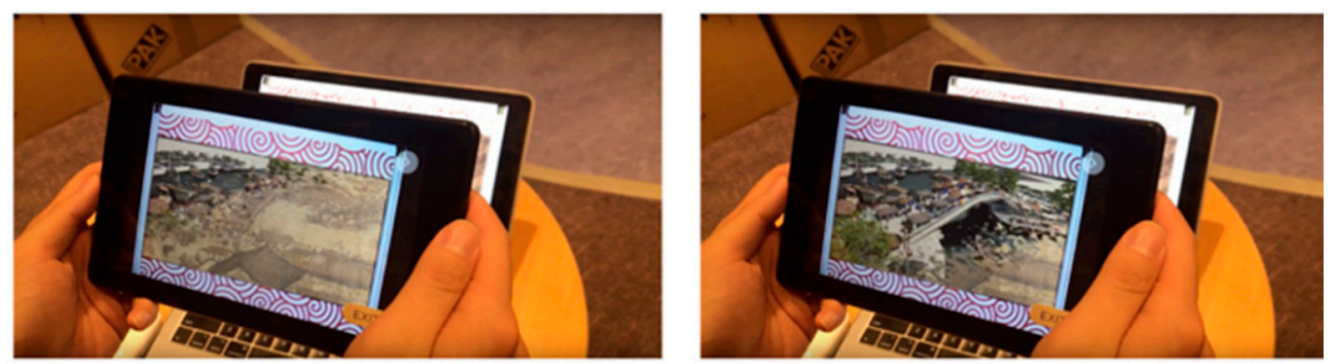

(a)
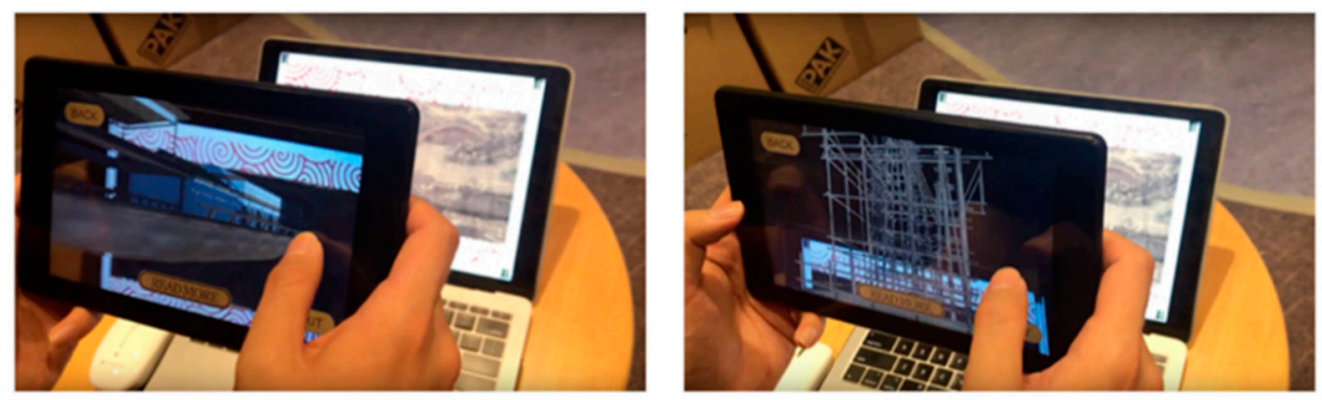

(b)
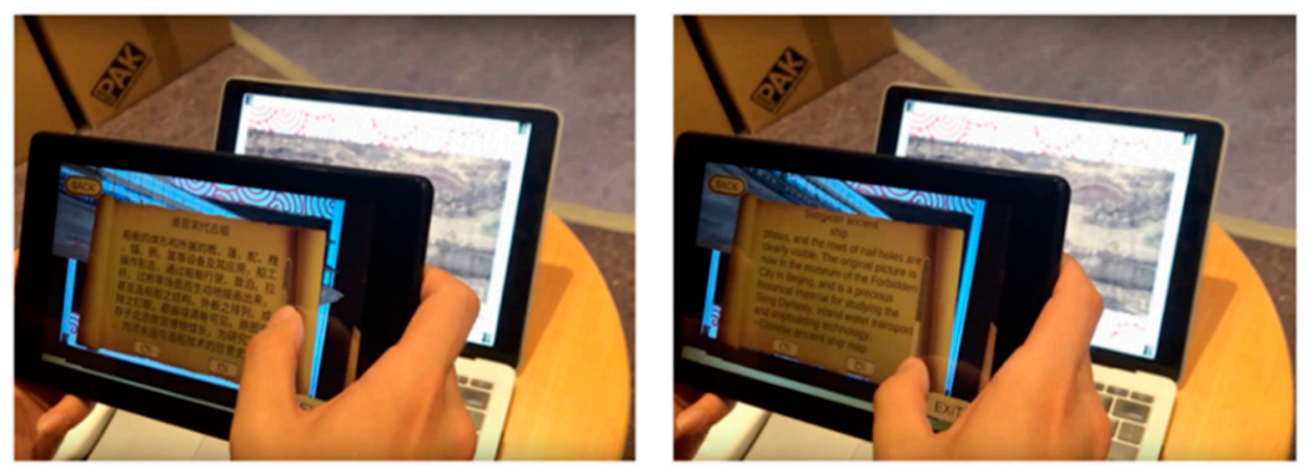

(c)

Figure 2. AR prototype created with Unity; (a) 3D animation; (b) AR ship and bridge; (c) further text- based information. (Demonstration link: https:/ / youtu.be/N4cHwtxan5M, accessed on 6 December 2021).

\subsection{Test}

The project was developed based on both the Android and IOS systems. Participants can use the tablet provided in the research to scan the Rainbow Bridge section of the painting. A 3D animation (Figure 2a) that overlays through AR will appear. Then, they can touch 
the elements to experience the interactive functions. For example, when participants touch the ship in the painting, an augmented reality ship will appear (Figure 2b). Additionally, participants can use their fingers to zoom in, zoom out, and even rotate the ship. Further, they can touch the button of the ship to acquire further text-based information concerning it (Figure 2c). The entire process is intended to be simple for the participants to navigate.

\subsection{Questionnaire}

The questions of the survey used in this research were constructed by reviewing questions used in the study by Othman Othman [36] named Museum Experience Scale (MES) (Table 1). The questionnaire indicates to what extent visitors agree with each of the following declarations about their attitudes towards interactive visualized information of Along the River During the Qingming festival using AR, compared with a viewing of the original painting with a text-based context. For each statement, they selected one of the responses: Strongly Disagree (coded as 1), Disagree (coded as 2), Neutral (coded as 3), Agree (coded as 4), and Strongly Agree (coded as 5). The last question was designed for visitors to provide further suggestions. Four components of museum experience emerged from the questionnaire:

- Engagement with the painting;

- Knowledge/ Learning gain from understanding and information discoveries;

- Meaningful Experience from the interaction with the painting;

- Emotional Connection with the context and content of the painting.

Table 1. Improved Museum Experience Scale (IMES).

\begin{tabular}{|c|c|}
\hline Engagement & Knowledge/Learning \\
\hline I enjoyed visiting the exhibition in relation to the painting. & The information provided about the information exhibits was clear. \\
\hline I felt engaged with the painting. & $\begin{array}{l}\text { I could make sense of most of the things I saw and did at } \\
\text { the exhibition. }\end{array}$ \\
\hline My visit to the painting exhibition was very interesting. & I liked the graphics associated with the exhibition. \\
\hline $\begin{array}{l}\text { I felt I was experiencing the painting exhibition, rather } \\
\text { than just visiting it. }\end{array}$ & $\begin{array}{l}\text { My visit enriched my knowledge and understanding of specific } \\
\text { elements regarding the details of the painting. }\end{array}$ \\
\hline My visit to the exhibition was inspiring. & $\begin{array}{l}\text { I discovered new information in relation to Along the reviver during } \\
\text { Qingming Festival from the exhibits. }\end{array}$ \\
\hline Meaningful Experience & Emotional Connection \\
\hline $\begin{array}{l}\text { During my visit, I was able to reflect on the significance of } \\
\text { the AR in the educational experience design. }\end{array}$ & $\begin{array}{l}\text { The exhibition enabled me to evoke my emotions and memories, } \\
\text { which may lead me to places that I might be unconsciously } \\
\text { interested in. }\end{array}$ \\
\hline
\end{tabular}

During my visit, I put a lot of effort into thinking about the single elements of the work including the ship, building and etc.

My sense of being in the painting was stronger than just look at the painting.

Seeing the AR prototype gave me a sense of wonder about the exhibition.

I was overwhelmed with the aesthetic/beauty aspect of the painting.

After visiting the exhibition, I was still interested to know more about the topic of the painting.

I wanted to own exhibits like those that I saw in the exhibition.

Seeing real data exhibits of importance was the most satisfying aspect of my visit to the exhibition.

I felt connected with the painting.

Reponses were based on a five-point scale with $1=$ not at all and $5=$ very much. Positive scale: $4-5$; Negative scale: $1-2$.

\subsection{Procedure}

A total of 58 Masters students $(21-25$-year-old, median $=24)$ were invited to test the prototype, comprising 29 males $(21-24$-year-old, median $=22.5)$ and 29 females $(21-25$-yearold, median $=24$ ). Additionally, the participants in this study were a mix of iPhone and 
Android users. All participants are Chinese students with media and art backgrounds, and none of them is familiar with the painting. Before the user test section, participants were given a demonstration of how to use the Tablet by the author.

To avoid the learning effects, participants were divided into two groups with equal numbers of participants: Group A (non-AR group, 29 participants including 14 females and 16 males), Group B (AR group, 29 participants including 14 females and 16 males).

Participants in Group A were then asked to view the paper painting work on the wall and read the additional text-based information provided by the study. People in Group B were asked to use the Tablet to scan the prepared AR-target painting work. By the end of the session, all of them were asked to complete the MES questionnaires.

\section{Results}

In this study, we compared the experience of participants from Group A (non-AR group) and Group B (AR group). T-test was performed to show the statistical significance of the differences between Group A and Group B. Different trends between Group A and Group B were displayed in Figure 3. The pairwise comparison results are shown in Table 2. Generally, from the results shown in Table 2, it can be concluded that there were significant increases in the mean scores across all four components between the two groups. In terms of the results of the engagement component, the use of AR technology can make people's information perception process more attractive in an informal learning environment. From the results of the knowledge/learning component, the combination of AR technology with oral narrative, 3D models and animations not only improve people's motivation and interest in learning in an informal educational environment but also motivates people to carry out a higher level of the learning process. Meaningful experience has grown most significantly compared to the other three components, illustrating that AR technology allows visitors to participate in the museum experience to the maximum extent possible and generate rich interactions with exhibits. Concerning the emotional connection component, AR technology significantly stimulates the visitor's emotional connection with the exhibits during the museum learning process.

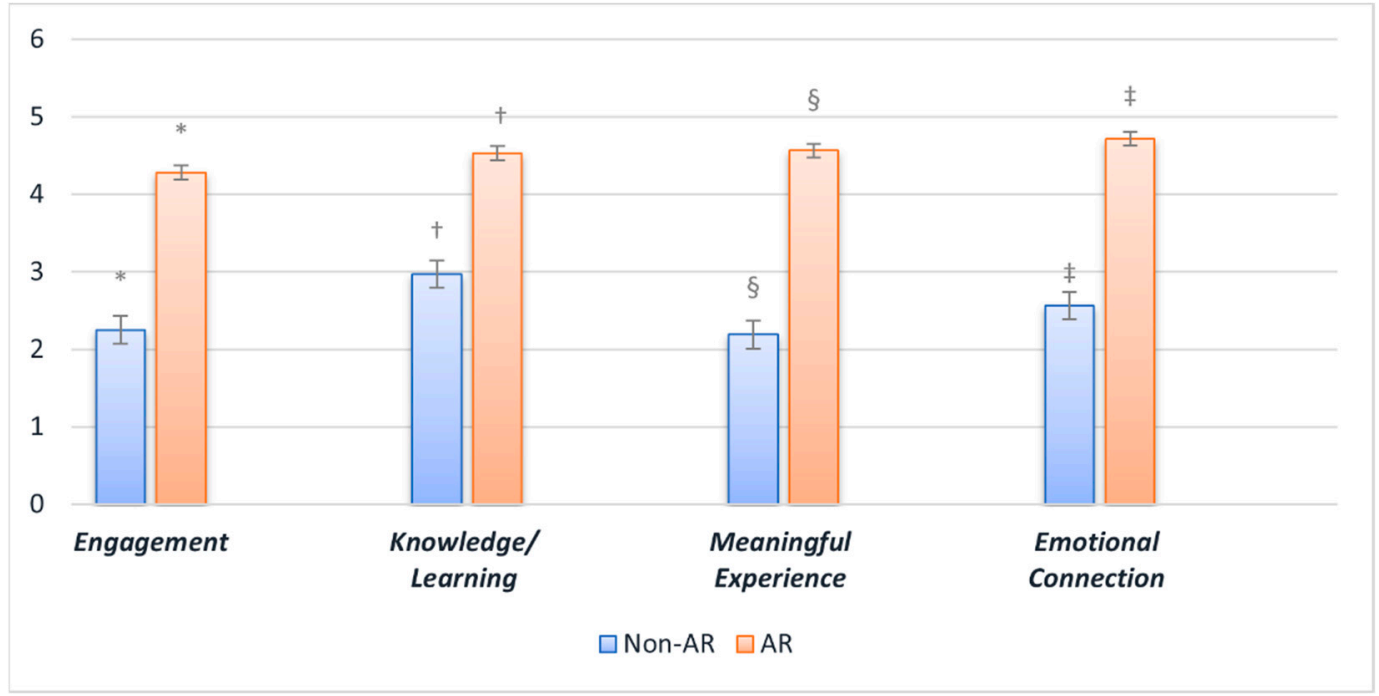

Figure 3. Mean \pm standard error of participants' responses in terms of mean Engagement, Knowledge/Learning, Meaningful Experience, and Emotional Connection scores, as measured by MES between the paper version painting (blue bars) and AR prototype (orange bars). Symbols $\left({ }^{*}, \uparrow, \S, \ddagger\right)$ indicated significant difference (at 0.05 level). 
Table 2. This table presents pairwise comparisons for results of responses in participants' Engagement, Knowledge/Learning, Meaningful Experience, and Emotional Connection, as measured by MES between the paper version painting and AR prototype.

\begin{tabular}{lllllll}
\hline & Mean & Std. Deviation & Std. Error Mean & $\boldsymbol{t}$ & Df & Sig. \\
\hline Engagement: Non-AR vs. AR & -2.031 & 1.092 & 0.193 & -10.522 & 31 & 0.000 \\
\hline Learning: Non-AR vs. AR & -1.563 & 1.076 & 0.190 & -8.216 & 31 & 0.000 \\
\hline Meaningful: Non-AR vs. AR & -2.375 & 1.100 & 0.194 & -12.215 & 31 & 0.000 \\
\hline Emotional connection: Non-AR vs. AR & -2.156 & 0.920 & 0.163 & -13.263 & 31 & 0.000 \\
\hline
\end{tabular}

To be specific, Figure 3 shows a significant increase in participants' engagement, knowledge/learning, meaningful experience and emotional connection between non-AR and AR groups $(\mathrm{N}=58, p<0.005)$. According to Antoniou et al. [41], although gender is not considered by museum experts to be a vital factor in appreciating museum content, gender might affect the user experience to some extent. Antoniou et al. [41] found that gender is highly correlated with the text design style preferences of personalised applications of the museum. Females appear more receptive to more interesting and informal text or narrative styles, while males prefer standard and formal text styles. Therefore, we also analysed the mean score between male and female participants (Figure 4). However, no significant distinction was found between the two groups.

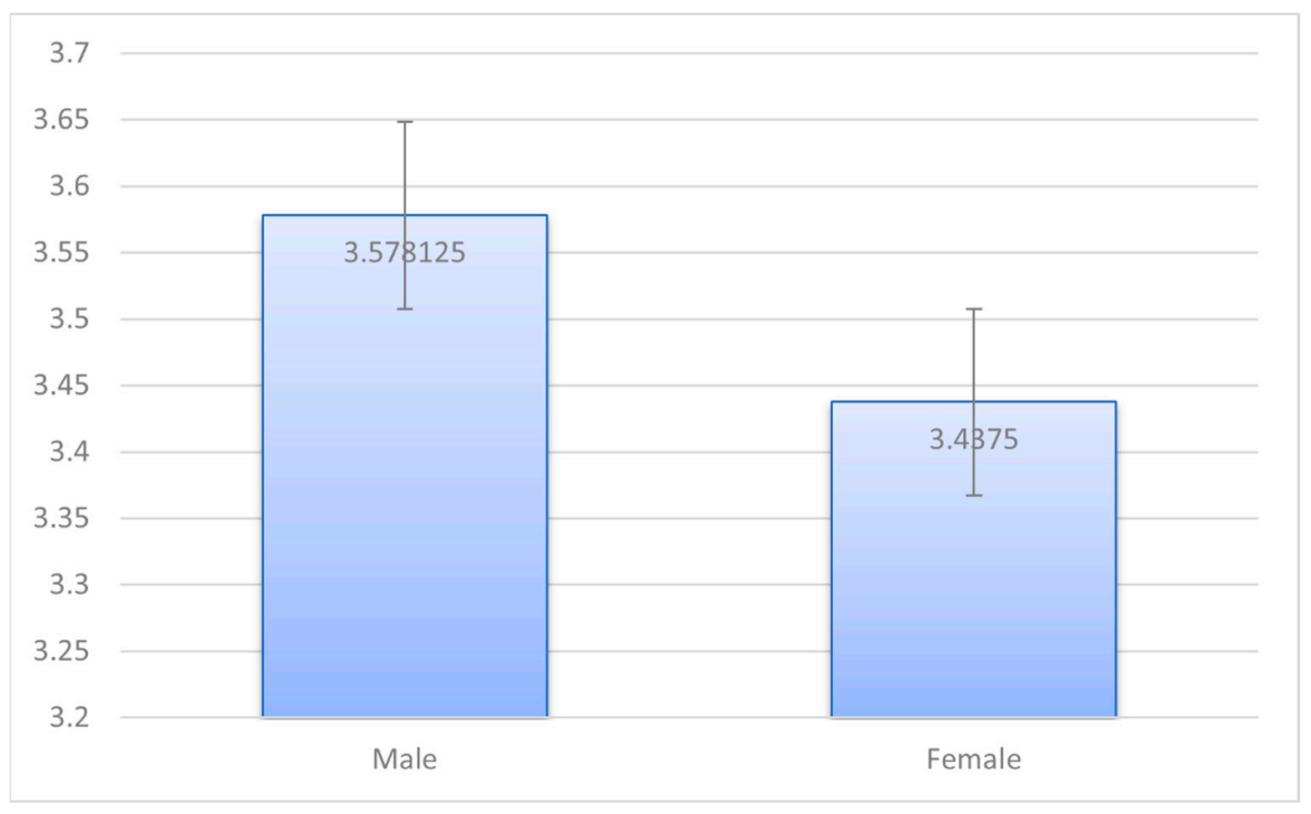

Figure 4. Mean scores between male and female participants.

\section{Discussion}

This study was conducted to explore the effectiveness of AR as a tool for triggering people's museum experience with a particular focus on their engagement, learning, meaningful experience, and emotional connection. Our results clearly show that people's engagement, learning, meaningful experience, and emotional connection have significantly increased when using the AR prototype. Furthermore, our results emerging from MES are significant. They can be useful in helping researchers and designers in their understanding of the use of AR as an engaging tool for information visualization.

\subsection{Engagement}

Learning engagement can be described as the stimulation of active learning by learners. Specifically, an active learner can automatically produce positive learning outcomes [42]. 
Our results in the engagement component show a significant difference between the nonAR group and the AR group. Our results also suggested that AR technology can make people's information input processes more engaging. Furthermore, it was also suggested that using AR in informal learning environments such as museums and galleries can make the visiting experience more attractive for visitors. Moreover, our results support a previous study by Wojciechowski et al. Wojciechowski, et al. [43], who created virtual and augmented reality exhibits that allow museum visitors to interact with the content exhibit in an authentic form. Additionally, the results potentially support Yusoff and Dahlan Yusoff and Dahlan [42], who suggest AR technology can effectively help learning engagement among students in generating focus during the learning process. It can be concluded that the sense and level of learning engagement can not only be affected by factors such as motivation, interest, previous knowledge but also by technology. In this sense, technology stimulates motivation and interest, leading to better engagement and outcomes.

\subsection{Knowledge and Learning}

The results from MES (Figure 3) indicate that using AR technology can motivate participants' knowledge and learning experience in terms of a relatively higher score when using the AR prototype. Our results support previous research by Pérez-López and Contero Pérez-López and Contero [44]. They suggest that using AR applications combining oral explanations, 3D models, and animations can improve students' motivation and interest, which leads to a high level of learning and teaching processes. Additionally, our results provide further evidence to contradict Othman's Othman [36] results; he found that there was no significant increase in people's knowledge and learning when using a digital guide in a museum.

\subsection{Meaningful Experience}

The results of meaningful experience evaluate visitors' level of interaction with the painting. As a significant feature of AR, interaction was first discussed by Falk and Dierking Falk and Dierking [45]. It is influenced, contextually, both personally and socially, and the result is the experience that is to be had by visitors. Interactive experience models ensure that visitors' experiences are not merely passive but dynamic in nature; they merge experiences before, during, and after the visit [8]. From our results, it is obvious that using AR technology to visualize hidden information about the exhibit can have a positive influence on people's meaningful experience (Figure 3). Additionally, the meaningful experience component results show the most significant increase among the other three components. Therefore, it can be said that maximizing participation and interaction opportunities during visits might enrich the overall experience for museum users.

\subsection{Emotional Connection}

Psychological literature has shown that mood and emotions can significantly impact the cognitive process [43,44]. Interestingly, our results from Figure 3 show a significant increase in the component of emotional connection before and after using the AR prototype. It is suggested that the application of AR technology can effectively trigger people's emotional connection with exhibits; therefore, it can motivate people's cognitive learning processes.

\section{Conclusions}

To support visitors' learning purpose in the informal educational environment, museums favour modern digital technology to stimulate the interaction between visitors and exhibits, thereby attracting visitors' interest and the museum learning experience. To satisfy the visitors' cognition and learning experience of ancient art pieces and provide museums with an efficient and low-cost way to display exhibits using modern digital technology. This research aims to develop a prototype of an application for a famous Chinese art piece named Along the River During the Qingming Festival. The development of this prototype 
considers the current trend of digital technology, namely, based on augmented reality. The overall results of this study indicate that, compared with traditional viewing, the interactive AR-assisted experience of the painting arouses visitors' curiosity and interest. Almost all of the participants felt that their viewing experience was enhanced through AR. However, although there was a wealth of text-based information about the painting displayed on the screen, some users indicated that they do not particularly like to read a lot when visiting museums. As concerns the efficacy of the learning support offered by AR, the general feedback was that the concept of providing such visual learning support could be successful. AR can support visitors' learning by giving suitable digital visual aids, particularly useful for engaging visitors when a large amount of information is attached to an exhibit. However, the design of the AR painting may require a clear search strategy and guidance for visitors. In the process of testing the AR prototype, a majority of the participants were found to manage the device easily. However, there were still two participants who needed continual coaching on how to use the system. So, it is clear that augmented reality in museums must follow specific strategies, or it may distract people concerning the design of the user interface and user. However, due to the time restrictions on the project, only a small segment of the painting could be digitally reproduced, and many of the intended functions were not achieved. This prototype could be applied to the whole painting Along the River During the Qingming Festival and to other similar paintings. Where this is conducted, the researcher offers some suggestions for its successful application. Firstly, a method should be found so that the porotype can be entirely constructed via AR, that is, to enable all the elements to be displayed in real-time. In addition, more research into the design of the user interface and user experiences is necessary to make visitors' use of the technology simpler. For instance, usability tests of museum visitors should be carried out based on AR application prototypes to obtain user opinions on the prototype design and the existing problems. This further iteratively designs and refines the user experience for the prototype. Furthermore, developing it from one painting work to an APP in museums would be very useful.

Author Contributions: Conceptualization, Z.G. and R.W.; methodology, G.X.; software, R.W., Z.G., and G.X.; validation, Z.G. and R.W.; formal analysis, G.X. and R.W.; data curation, Z.G.; writingoriginal draft preparation, Z.G.; writing—review and editing, G.X., R.W. and Z.G.; supervision, G.X. All authors have read and agreed to the published version of the manuscript.

Funding: This research received no external funding.

Institutional Review Board Statement: The study was approved by the Ethics Committee of University of Leeds (protocol code LTDESN-125).

Informed Consent Statement: Informed consent was obtained from all subjects involved in the study.

Data Availability Statement: The data presented in this study are available on request from the corresponding author.

Acknowledgments: We appreciate all the participants who took part in the experiment.

Conflicts of Interest: The authors declare no conflict of interest. 


\section{Appendix A}

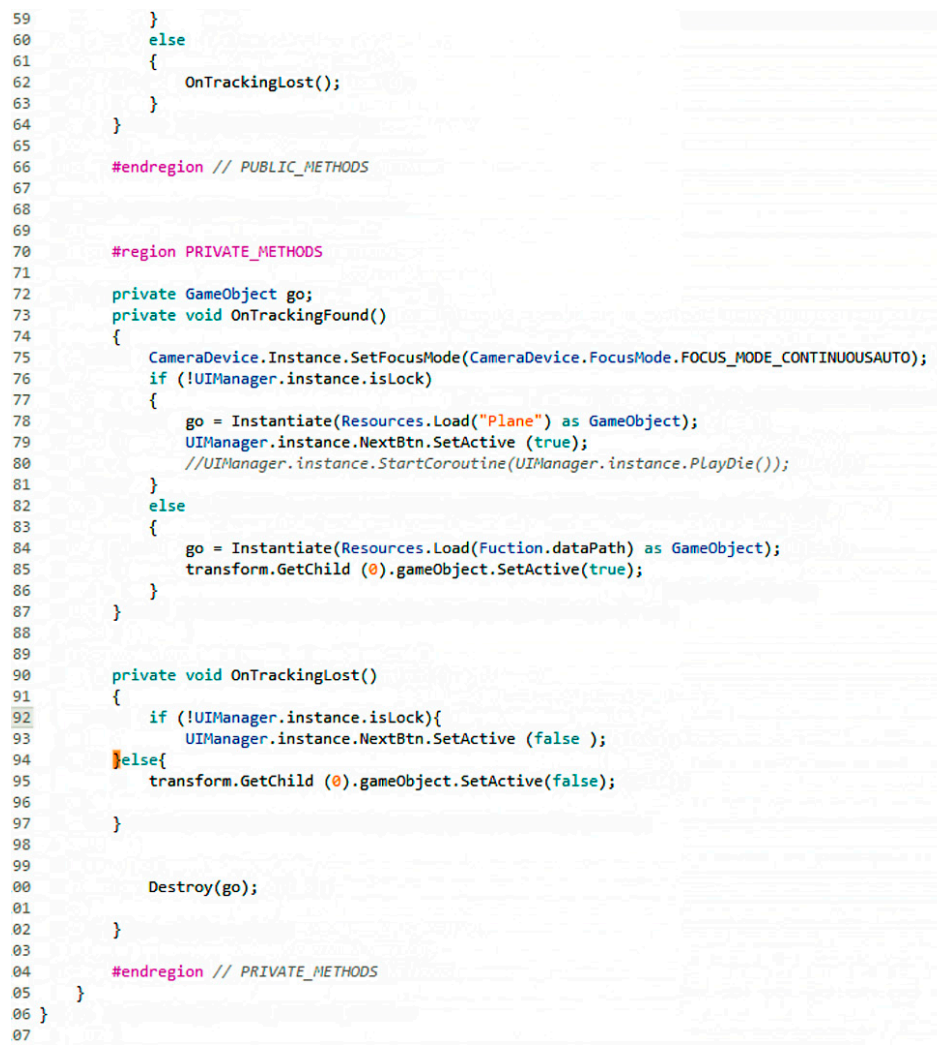

Figure A1. The code shown above was used to model the appear and disappear function of objects.

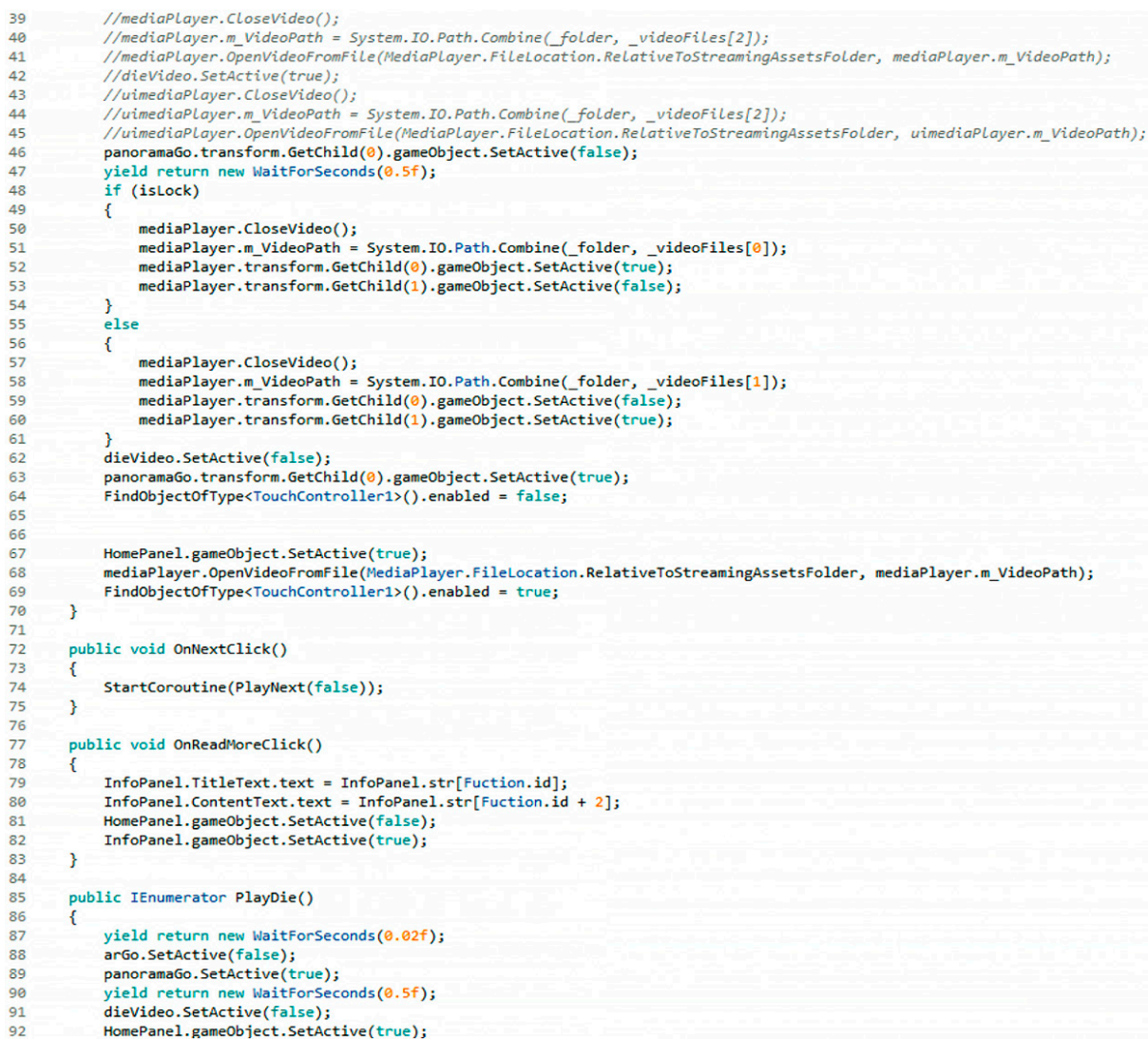

Figure A2. The above code was used to perform the switch between video and video. 


\section{References}

1. He, Z.; Wu, L.; Li, X.R. When art meets tech: The role of augmented reality in enhancing museum experiences and purchase intentions. Tour. Manag. 2018, 68, 127-139. [CrossRef]

2. Neuburger, L.; Egger, R. Augmented reality: Providing a different dimension for museum visitors. In Augmented Reality and Virtual Reality; Springer: New York, NY, USA, 2018; pp. 65-77.

3. Neuburger, L.; Egger, R. An afternoon at the museum: Through the lens of augmented reality. In Information and Communication Technologies in Tourism 2017; Springer: New York, NY, USA, 2017; pp. 241-254.

4. Black, G. The Engaging Museum: Developing Museums for Visitor Involvement; Psychology Press: Hove, UK, 2005.

5. Hinrichs, U.; Schmidt, H.; Carpendale, S. EMDialog: Bringing Information Visualization into the Museum. IEEE Trans. Vis. Comput. Graph. 2008, 14, 1181-1188. [CrossRef] [PubMed]

6. Hornecker, E.; Stifter, M. Learning from interactive museum installations about interaction design for public settings. In Proceedings of the 18th Australia conference on Computer-Human Interaction: Design: Activities, Artefacts and Environments, Sydney, Australia, 20-24 November 2006; pp. 135-142.

7. Liu, W.C. Visitor study and operational development of museums. Museol. Q. 2008, 22, 21-37.

8. Horn, M.S.; Phillips, B.C.; Evans, E.M.; Block, F.; Diamond, J.; Shen, C. Visualizing biological data in museums: Visitor learning with an interactive tree of life exhibit. J. Res. Sci. Teach. 2016, 53, 895-918. [CrossRef]

9. Chen, C. Information visualization. Wiley Interdiscip. Rev. Comput. Stat. 2010, 2, 387-403. [CrossRef]

10. Ward, M.O.; Grinstein, G.; Keim, D. Interactive Data Visualization: Foundations, Techniques, and Applications; AK Peters: Natick, MA, USA; CRC Press: Boca Raton, FL, USA, 2015.

11. Hearst, M. Search User Interfaces; Cambridge University Press: Cambridge, UK, 2009.

12. Card, M. Readings in Information Visualization: Using Vision to Think; Morgan Kaufmann: Burlington, MA, USA, 1999.

13. Heer, J.; Bostock, M.; Ogievetsky, V.J.C. A tour through the visualization zoo. ACMQueue 2010, 53, 59-67. [CrossRef]

14. Xia, G.; Yu, L.; Gong, Z.; Zhang, Y.; Zhang, S.; Zhu, Z.; Li, H.; Tang, Y.; Huang, Y.; Tian, Z. Designing with biodiversity data: Connections among design, materials, and technology. Int. J. Inf. Technol. 2021, 13, 1703-1710. [CrossRef]

15. Tomiuc, A. Navigating Culture. Enhancing Visitor Museum Experience through Mobile Technologies. From Smartphone to Google Glass. J. Media Res. 2014, 7, 33-46.

16. Lin, H.-C.K.; Hsieh, M.-C.; Liu, E.Z.-F.; Chuang, T.-Y. Interacting with Visual Poems through AR-Based Digital Artwork. Turk. Online J. Educ. Technol. 2012, 11, 123-137.

17. Azuma, R.T. A survey of augmented reality. Presence: Teleoperators Virtual Environ. 1997, 6, 355-385. [CrossRef]

18. Rosenbaum, E.; Klopfer, E.; Perry, J. On location learning: Authentic applied science with networked augmented realities. J. Sci. Educ. Technol. 2007, 16, 31-45. [CrossRef]

19. Sotiriou, S.; Bogner, F. Visualizing the Invisible: Augmented Reality as an Innovative Science Education Scheme. Adv. Sci. Lett. 2008, 1, 114-122. [CrossRef]

20. Dunleavy, M.; Dede, C.; Mitchell, R. Affordances and limitations of immersive participatory augmented reality simulations for teaching and learning. J. Sci. Educ. Technol. 2009, 18, 7-22. [CrossRef]

21. Shelton, B.E.; Hedley, N.R. Using augmented reality for teaching earth-sun relationships to undergraduate geography students. In Proceedings of the The First IEEE International Workshop Agumented Reality Toolkit, Darmstradt, Germany, 29 September 2002; p. 8.

22. Dunleavy, M.; Dede, C. Augmented reality teaching and learning. In Handbook of Research on Educational Communications and Technology; Springer: New York, NY, USA, 2014; pp. 735-745.

23. Kotranza, A.; Lind, D.S.; Pugh, C.M.; Lok, B. Real-time in-situ visual feedback of task performance in mixed environments for learning joint psychomotor-cognitive tasks. In Proceedings of the 2009 8th IEEE International Symposium on Mixed and Augmented Reality, Orlando, FL, USA, 19-22 October 2009; pp. 125-134.

24. Bujak, K.R.; Radu, I.; Catrambone, R.; MacIntyre, B.; Zheng, R.; Golubski, G. A psychological perspective on augmented reality in the mathematics classroom. Comput. Educ. 2013, 68, 536-544. [CrossRef]

25. Chien, C.-H.; Chen, C.-H.; Jeng, T.-S. An interactive augmented reality system for learning anatomy structure. In Proceedings of the proceedings of the international multiconference of engineers and computer scientists, Hong Kong, China, 17-19 March 2010; pp. 17-19.

26. Arvanitis, T.N.; Petrou, A.; Knight, J.F.; Savas, S.; Sotiriou, S.; Gargalakos, M.; Gialouri, E. Human factors and qualitative pedagogical evaluation of a mobile augmented reality system for science education used by learners with physical disabilities. Pers. Ubiquitous Comput. 2009, 13, 243-250. [CrossRef]

27. Chang, K.-E.; Chang, C.-T.; Hou, H.-T.; Sung, Y.-T.; Chao, H.-L.; Lee, C.-M. Development and behavioral pattern analysis of a mobile guide system with augmented reality for painting appreciation instruction in an art museum. Comput. Educ. 2014, 71, 185-197. [CrossRef]

28. El Sayed, N.A. Applying Augmented Reality Techniques in the Field of Education: ARSC Augmented Reality Student Card an Augmented Reality Solution for The Education Field. Available online: https://dl.acm.org/doi/abs/10.5555/2161849 (accessed on 6 December 2021).

29. Gimeno, J.; Portalés, C.; Coma, I.; Fernández, M.; Martínez, B. Combining traditional and indirect augmented reality for indoor crowded environments. A case study on the Casa Batlló museum. Comput. Graph. 2017, 69, 92-103. [CrossRef] 
30. Guazzaroni, G.; Pillai, A.S. Virtual and Augmented Reality in Education, Art, and Museums; IGI Global: Harshey, PA, USA, 2019.

31. Portalés, C.; Lerma, J.L.; Pérez, C. Photogrammetry and augmented reality for cultural heritage applications. Photogramm. Rec. 2009, 24, 316-331. [CrossRef]

32. White, M.; Mourkoussis, N.; Darcy, J.; Petridis, P.; Liarokapis, F.; Lister, P.; Walczak, K.; Wojciechowski, R.; Cellary, W.; Chmielewski, J. ARCO-an architecture for digitization, management and presentation of virtual exhibitions. In Proceedings of the Computer Graphics International, Crete, Greece, 14-18 March 2004; pp. 622-625.

33. Kenteris, M.; Gavalas, D.; Economou, D. Electronic mobile guides: A survey. Pers. Ubiquitous Comput. 2011, 15, 97-111. [CrossRef]

34. Panou, C.; Ragia, L.; Dimelli, D.; Mania, K. An architecture for mobile outdoors augmented reality for cultural heritage. ISPRS Int. J. Geo-Inf. 2018, 7, 463. [CrossRef]

35. Othman, M.K. Measuring Visitors' Experiences with Mobile Guide Technology in Cultural Spaces. Ph.D. Thesis, University of York, York, UK, 2012.

36. Jung, K.; Nguyen, V.T.; Piscarac, D.; Yoo, S.-C. Meet the virtual Jeju Dol Harubang-The mixed VR/AR application for cultural immersion in Korea's main heritage. ISPRS Int. J. Geo-Inf. 2020, 9, 367. [CrossRef]

37. Venigalla, A.S.M.; Chimalakonda, S. Towards enhancing user experience through a web-based augmented reality museum. In Proceedings of the 2019 IEEE 19th International Conference on Advanced Learning Technologies (ICALT), Maceio, Brazil, 15-18 July 2019; pp. 357-358.

38. Pan, Z.; Jiang, R.; Liu, G.; Shen, C. Animating and interacting with ancient Chinese painting-Qingming festival by the riverside. In Proceedings of the 2011 Second International Conference on Culture and Computing, Kyoto, Japan, 20-22 October 2011; pp. 3-6.

39. Antoniou, A.; Katifori, A.; Roussou, M.; Vayanou, M.; Karvounis, M.; Kyriakidi, M.; Pujol-Tost, L. Capturing the visitor profile for a personalized mobile museum experience: An indirect approach. In Enlighten; University of Glasgow: Glasgow, UK, 2016.

40. Yusoff, Z.; Dahlan, H.M. Mobile based learning: An integrated framework to support learning engagement through Augmented Reality environment. In Proceedings of the 2013 International Conference on Research and Innovation in Information Systems (ICRIIS), Kuala Lumpur, Malaysia, 27-28 November 2013; pp. 251-256.

41. Wojciechowski, R.; Walczak, K.; White, M.; Cellary, W. Building virtual and augmented reality museum exhibitions. In Proceedings of the Ninth International Conference on 3D Web Technology, New York, NY, USA, 5 April 2004; Assocoation for Computing Machinery: New York, NY, USA, 2004; pp. 135-144.

42. Pérez-López, D.; Contero, M.J. Delivering educational multimedia contents through an augmented reality application: A case study on its impact on knowledge acquisition and retention. Turk. Online J. Educ. Technol. 2013, 12, 19-28.

43. Falk, J.H.; Dierking, L.D. The Museum Experience Revisited; Routledge: Milton Park, UK, 2016.

44. Clark, M.S.; Fiske, S.T. Affect and Cognition: 17th Annual Carnegie Mellon Symposium on Cognition; Psychology Press: Hove, UK, 1982.

45. Isen, A.M. Toward understanding the role of affect in cognition. In Handbook of Social Cognition; Lawrence Erlbaum Associates Publishers: Mahwah, NJ, USA, 1984. 